\title{
Design and management processes involved with extracting regional pillar stopes in a seismic setting at Darlot Gold Mine
}

\author{
C Moulding Gold Fields Australia Pty Ltd, Australia \\ P Andrews Gold Fields Australia Pty Ltd, Australia
}

\begin{abstract}
This paper outlines the protocols introduced for the management of potential seismic risk, including monitoring, numerical modelling, extraction sequencing and the necessary support upgrades to mitigate the risks at Darlot Gold Mine.
\end{abstract}

The Walters Lode is located $400 \mathrm{~m}$ below surface and uses a longhole mining method retreating back to a regional pillar. The lode is hosted within a strong dolerite host rock (uniaxial compressive strength $(U C S)=220 \mathrm{MPa}+$ ), with a UCS that often exceeds $200 \mathrm{MPa}$, with the main mineralised lode following along a structure called the first slip fault. This structure pinches and swells at varying depths and is usually identified by quartz intrusions and a $0.5-1.0 \mathrm{~m}$ sheared zoned along the plane. This fault dips at approximately $50^{\circ}$ to the west. In addition to the first slip fault, there are multiple intersecting faults throughout the area.

Originally the ground support for the development drives was not designed for seismic conditions and predominantly utilised resin bolts installed over fibrecrete. As the mining front began to retreat towards the pillar, mining induced stresses began acting upon the rock mass and the structures in the area. The rock mass response to these changes included an increase in seismic activity and deformation. This increased activity led to a review of the seismic management risk procedures at Darlot.

Initial changes included upgrading the ground support regime to a yielding system capable of retaining the rock mass in response to predicted levels of seismicity. Expected levels of seismicity were obtained by undertaking a review of historical seismic data in the area.

Non-linear elastic modelling was also undertaken to determine the potential seismic response and predicted damage to the rock mass based on the proposed extraction sequence. Based on these results, a geotechnically optimised stoping sequence was proposed.

Internal numerical modelling has been conducted to account for newly found stope shapes relative to the original extraction sequence. The results that show potential depths of failure are used to strategically plan and account for additional overbreak or brow damage in the mining plan.

Ongoing seismic monitoring and analysis is used to determine seismic exclusion zones and re-entry times.

All of the above changes are used to continually calibrate the existing models, and ongoing data collection has resulted in an optimal extraction sequence, therefore allowing a safe and productive extraction of the Walters Lode.

\section{Introduction}

The selected extraction method and mining sequence have a significant influence on the performance of deep underground stopes. The performance is primarily associated with stope geometry, field and induced stresses, geological structures, intact rock strength and rock mass characteristics. Darlot Gold Mine has mining areas that capture all of these performance factors, predominantly within the Walters Lode which has high induced stresses and complex structural conditions within a remnant mining zone. These factors have historically led to increased stope over break and an increased seismic response, that both affect 
production (i.e. time delay, increased cost, safety concerns). A set of management strategies and practices were implemented to manage these factors, including both elastic and non-linear numerical modelling to help geotechnical engineers optimise the stope geometry and extraction sequence. Additional administrative controls have also been implemented, such as exclusion zones and re-entry times to ensure seismic risk to personnel is mitigated. This paper presents an overview of the mine design, geological conditions, stress influences and management processes to safely extract the orebody.

\section{Darlot Gold Mine}

\section{$2.1 \quad$ Location}

Darlot Gold Mine is located $58 \mathrm{~km}$ east of Leinster, Western Australia. Since 1 October 2013, the mine has been owned by Darlot Mining Company Pty Ltd, an indirect subsidiary of Gold Fields Limited. Darlot began as an open pit operations in 1989, and underground operations commenced in 1995 under the Home Stake Mining Company when the Darlot orebody was discovered. Underground mining is now located in the Centenary orebody.

The mine is located at the southern end of the NNW trending Yandal Greenstone Belt of the Yilgarn Craton. Mining occurs along an orebody with a $1.5 \mathrm{~km}$ strike length, and active mining is conducted between 350 and $740 \mathrm{~m}$ below the ground surface. The Darlot mine utilises various extraction sequences throughout the mine which include longhole retreat, room and pillar, half echelon retreat, primary and secondary bulk stoping. The majority of these extraction sequences are complimented with cemented paste fill. The paste plant was commissioned in 2006, and stope filling allows for complete extraction of the orebody instead of leaving ore pillars behind.

\subsection{Geology}

Figure 1 shows the multiple ore zones currently extracted at Darlot. Gold mineralisation is predominately hosted in magnetic dolerite (85\%) and magnetic quartz dolerite (8\%). Mineralisation can also be found in the non-magnetic dolerite and felsic volcano-sedimentary rock types, typically in the following conditions:

- Narrow (0.2 to $30 \mathrm{~cm}$ wide) shallow westerly dipping (0 to $20^{\circ}$ ) stacked quartz veins.

- Massive (50 to $400 \mathrm{~cm}$ wide) banded quartz veins that dip at $60^{\circ}$ to the northwest.

The zone known as the Walters Lode is defined by a banded quartz vein. The vein varies from $50 \mathrm{~cm}$ to several metres in true thickness, with a $600 \mathrm{~m}$ strike length and extends $600 \mathrm{~m}$ down dip. Minor shallower dipping veining also occurs along the footwall (FW) and hanging wall (HW). The ore zone is hosted in very strong Dolerite (UCS $=220 \mathrm{MPa}+$ ) and is dominated by a regional fault structure known as the first slip fault. This fault varies in thickness with depth and is characterised by quartz intrusions, narrow alteration halos and a 0.5-1.0 m sheared contact zone along the plane. This leads to a poorer rock mass within the HW of stopes. 


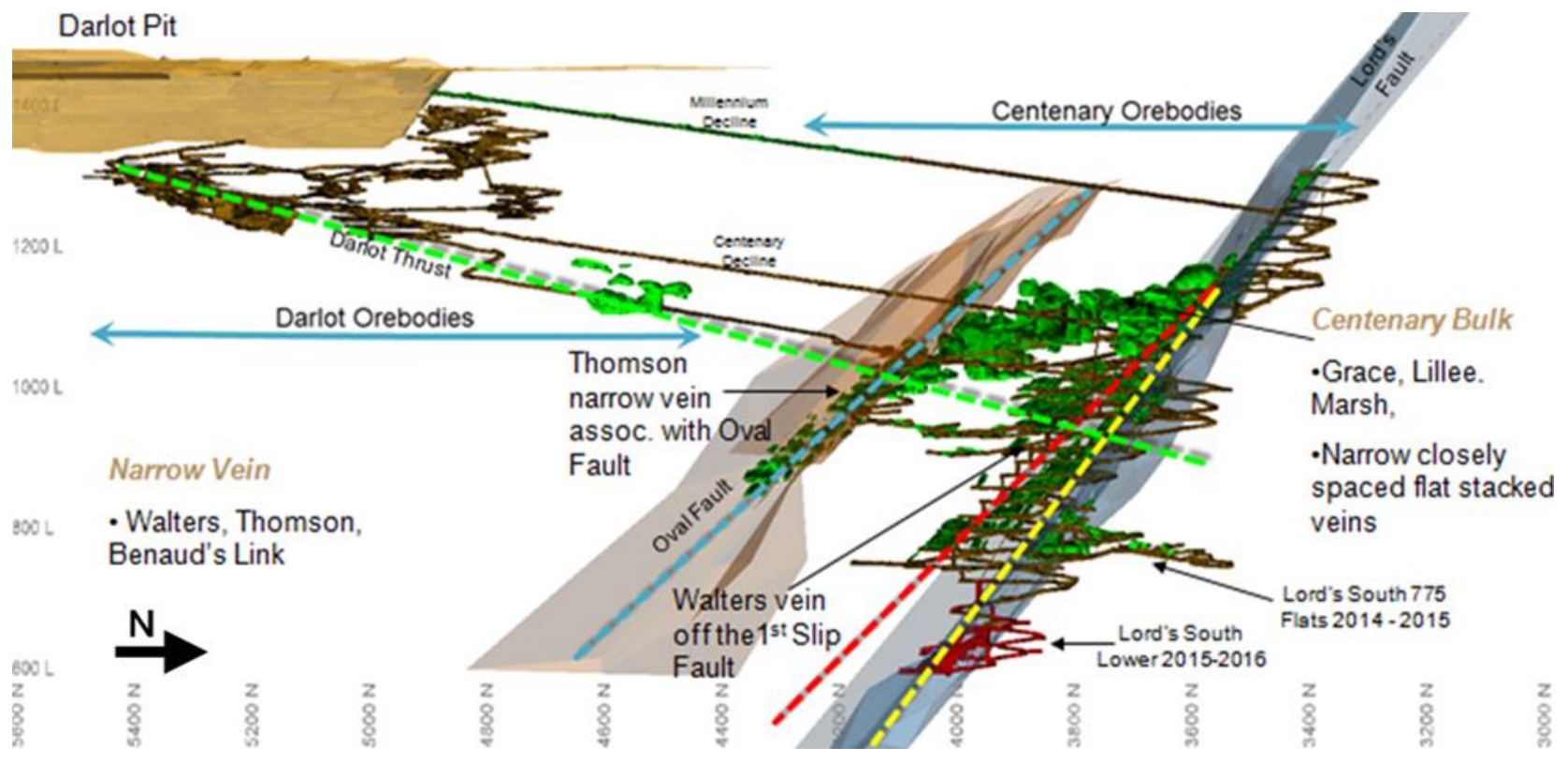

Figure 1 Darlot Gold Mine ore zones

\subsection{Walters extraction sequence}

The Walters Lode was initially designed for extraction using a longhole retreat method towards a central access, which created a closure pillar and is illustrated in Figure 2. This initial extraction sequence utilised waste rock and cemented aggregate fill to mine a bottom up sequence. Rib and sill pillars were also used if ground conditions warranted them. Once paste backfill was introduced in 2006, the mining sequence changed to a top down mining method. This did not change the central pillar scenario, but enabled improved control of the unsupported stope spans, reduced the stoping cycle time, and reduced the damaging effects on the rock mass which could lead to fracturing and increased support requirements.
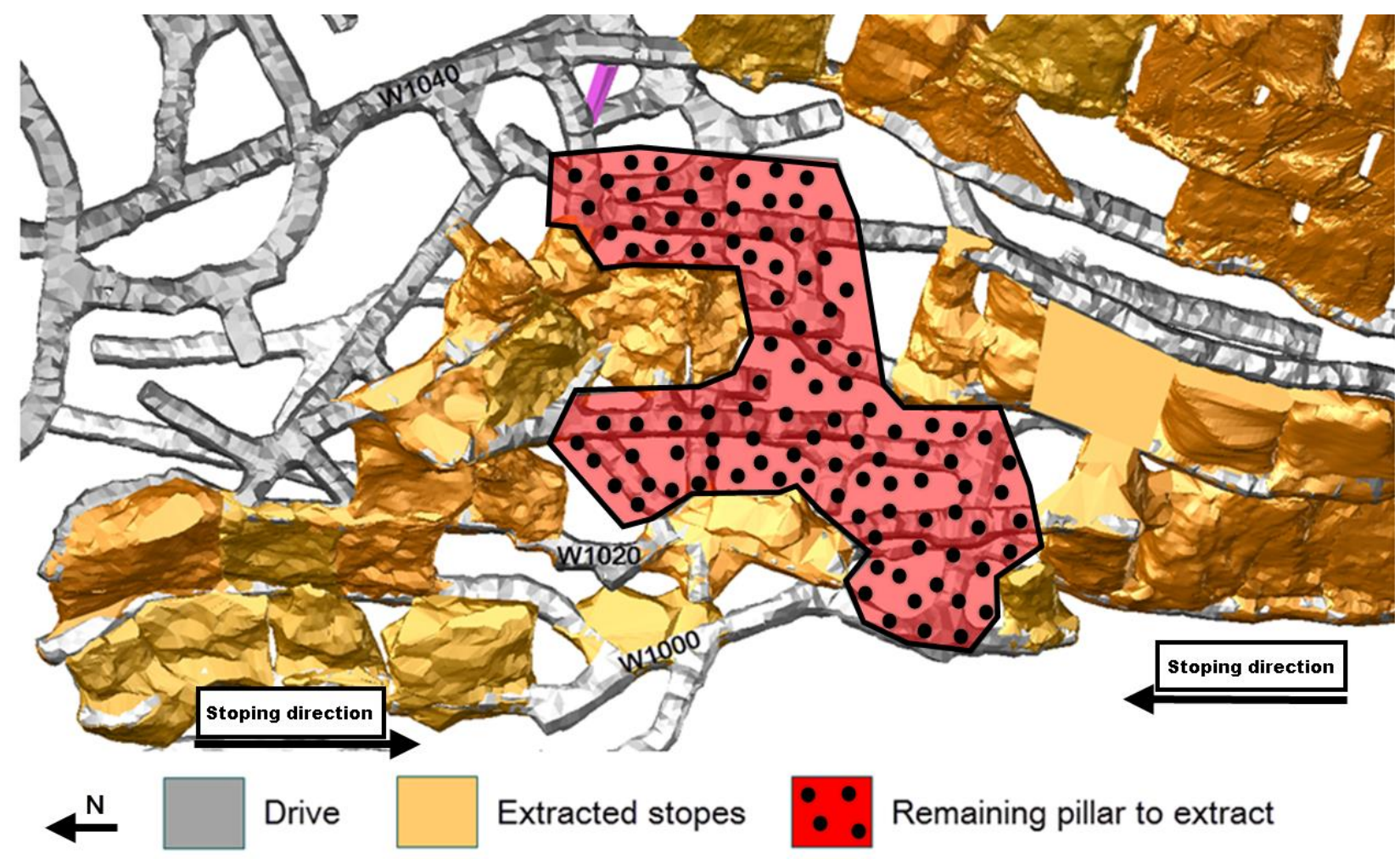

Remaining pillar to extract

Figure 2 The remaining pillar as of September 2014 
The paste fill strengths were designed for 5-7 $\mathrm{m}$ wide undercutting and mining beside exposures, using equations adapted from Mitchell and Roettger (1989).

As the extraction sequence progressed, the stresses concentrated in the central pillar and other adjacent sill/rib pillars between stopes. Options for an alternative extraction sequences were reviewed, but were found to be unsatisfactory due to the main decline location and other nearby mining fronts encroaching on the area and because it was uneconomical to develop FW drives to provide dual access to the orebody.

\subsubsection{Rock mass classification}

As shown in Table 1, the typical rock mass quality of the host Dolerite at Darlot Gold Mine has a Q-value of three based on the NGI Q-system (Barton et al. 1974). The NGI system classifies a Q-value of three as a 'poor' rock mass.

Table 1 Q-System for Dolerite host rock at Darlot Gold Mine

\begin{tabular}{|c|c|c|c|c|c|c|c|c|c|}
\hline Rock type & $\begin{array}{l}\text { RQD } \\
\text { (\%) }\end{array}$ & Joint set & Jn & $\begin{array}{l}\text { Joint } \\
\text { roughness }\end{array}$ & $\mathrm{Jr}$ & $\mathrm{Ja}$ & Jw & SRF & $\mathbf{Q}$ \\
\hline Dolerite & 90 & $\begin{array}{l}\text { Two sets plus } \\
\text { random }\end{array}$ & 6 & $\begin{array}{l}\text { Smooth } \\
\text { undulating }\end{array}$ & 2 & 4 & 1 & 2.5 & 3 \\
\hline
\end{tabular}

\subsubsection{Walters stope designs}

The stopes in the Walters Lode generally dip at $50^{\circ}$ with HW parallel to the first slip fault. This is because the primary failure mechanism within the stopes is gravity wedge/slab failures associated with the HW breaking to the fault contact. Darlot Gold Mine also has a dominant horizontal joint set which interacts with the moderately dipping structures in the HW and increases the likelihood of failures or overbreak. An example stope design, along with potential failure zones within the Walters Lode, are shown in Figure 3.

Moderately dipping stopes have been predominantly designed with a hydraulic radius (HR) of $5.0 \mathrm{~m}$ to plot within the stable zone of the modified stability chart. This HR has proved successful when extracting alongside the first slip fault $20 \times 20 \mathrm{~m}$ and allows a $20 \times 20 \mathrm{~m}$ HW exposure.

All flat stoping areas are considered unstable at spans greater than a HR of $4.5 \mathrm{~m}$. They have a higher risk, due to the increased potential of larger wedge failures, which can propagate up to the first slip fault. This HR constraint was put in place after a wedge failure within the Walters Lode stope occurred in early 2014. The stope was designed with a HR of $5.5 \mathrm{~m}$ with the first slip fault crossing the central backs at a $55^{\circ}$ angle of intersection. The ore was extracted slowly under the full HW exposure, instead of prioritising quick extraction. This led to a large wedge failure in the central backs which diluted the remaining ore source and resulted in a production loss. Figure 4 shows this predicted extent of failure in more detail.

A long 'stand-up time' played a critical role in the performance of the stope, all flat back stopes are now designed with a HR value no larger than $4.5 \mathrm{~m}$. The stope must be bogged clean between each firing and never left idle, or a production risk assessment must be completed to determine the production and financial impacts from potential wedge failures. 


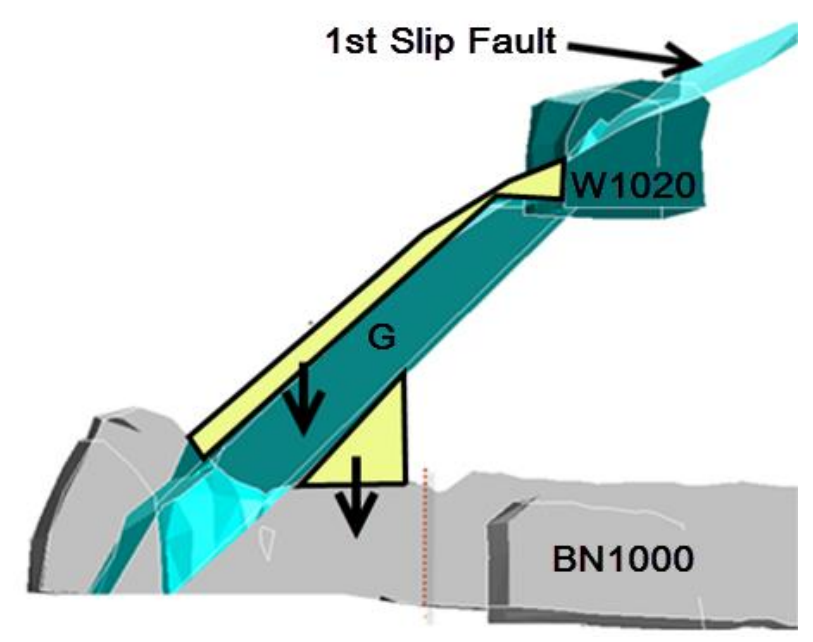

Figure 3 BN1000 HWN G Panel design cross-section

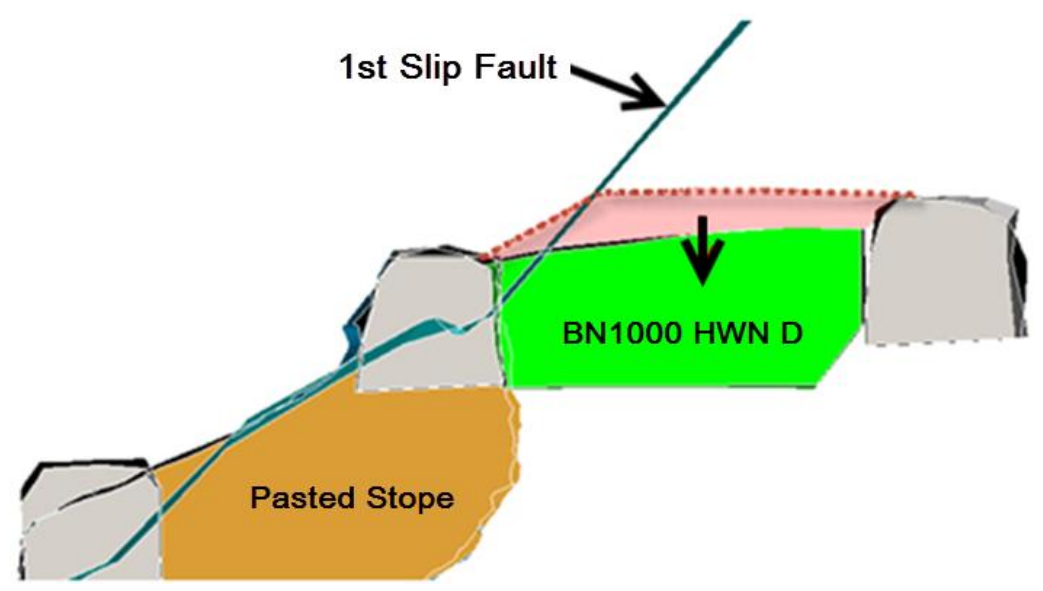

Figure 4 BN1000 HWN D failure scenario

\section{Seismicity}

Darlot Gold Mine installed four triaxial and twelve uniaxial sensors when it replaced an existing system with an Institute of Mine Seismology (IMS) seismic system in December 2009. This installation has provided a more consistent performance compared with the previous system which deteriorated to the point of failure in early 2009. The new system allowed for better analysis of all seismic parameters throughout the mine.

\subsection{Analysis}

As previously mentioned, the Walters Lode has one major and multiple smaller faults interacting with the ore zone, as illustrated in Figure 5. These smaller faults vary in seismic response as stope blasting occurs nearby. Back-analysis and review of the seismicity around the Walters Lode indicated that the first slip fault is the primary structure associated with seismicity.

Ongoing seismic analysis indicates extensive clustering on the first slip fault contact and in the HW rock mass, and it has also been calibrated as the source of the damaging seismic events. A summary of historical damaging seismic events within the stress window is displayed in Table 2.

The largest event 'recorded' on the system was an IMS local magnitude $\left(\mathrm{ML}_{\mathrm{L}}\right)$ of +1.3 on 20 February 2012, and it occurred forty minutes after firing a rise, which intersected the First Slip fault. This is illustrated in Figure 6. 

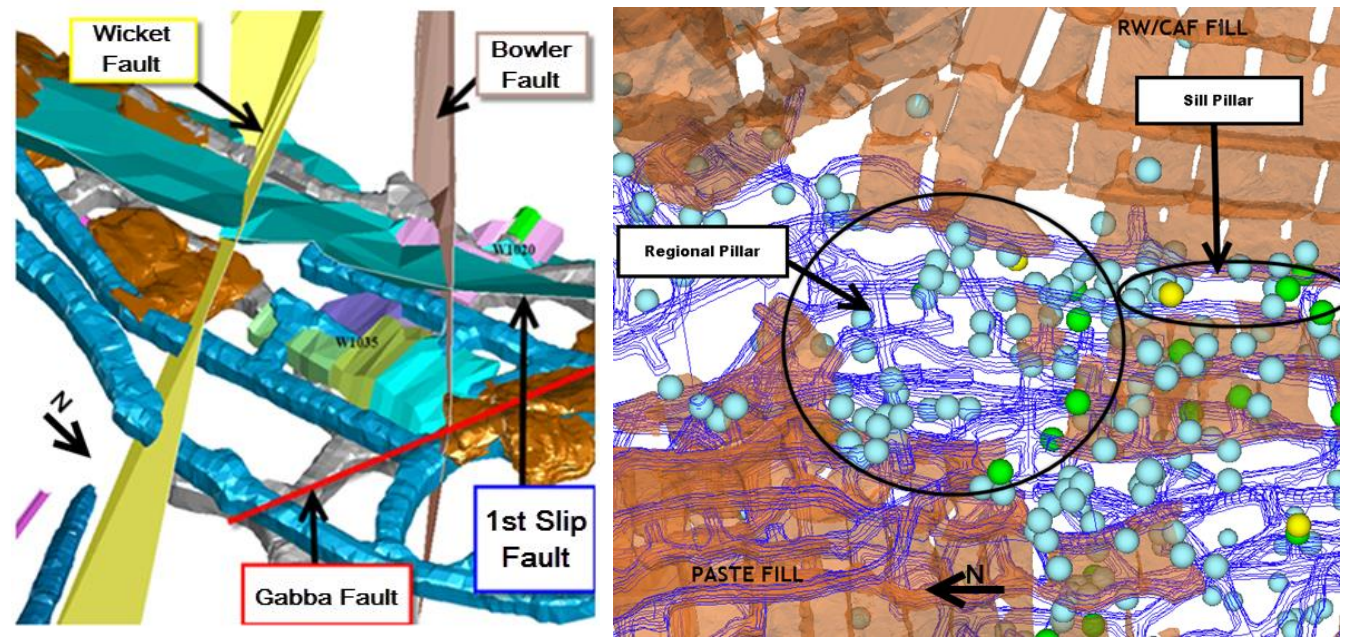

Figure 5 Fault structures and event distribution within the Walters Lode

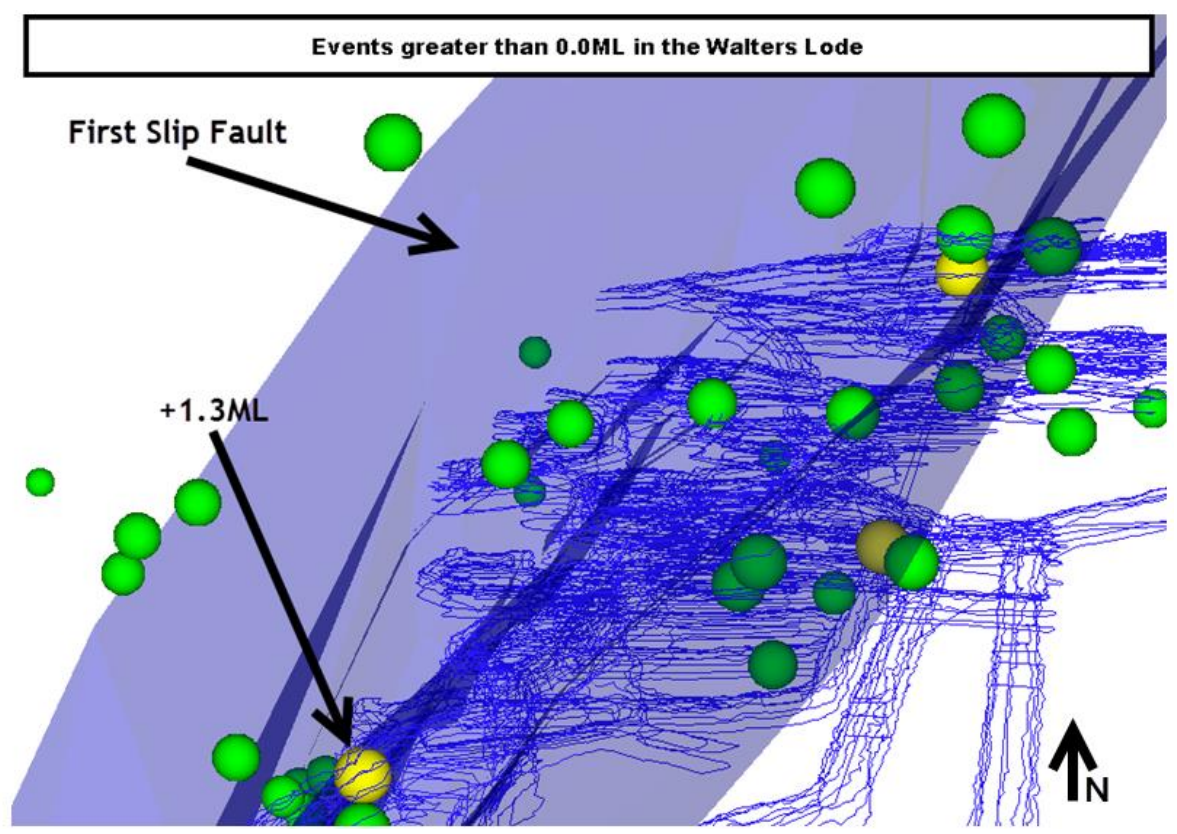

Figure 6 Seismic events $>0.0 \mathrm{ML}$ associated with first slip fault

Table 2 Summary of damaging seismic events within the stress window

\begin{tabular}{|c|c|c|}
\hline Date & Magnitude (ML) & Comment \\
\hline 18 February 2009 & $0.8-1.5$ & Pillar damage at W920 \\
\hline 18 May 2009 & 1.5 estimated & $\begin{array}{l}\text { Multiple events recorded, extensive damage } \\
\text { in W1000, W1020 and W1035 }\end{array}$ \\
\hline 29 July 2010 & 1.2 estimated & Damage to W1000 HWN stock pile \\
\hline 10 July 2011 & 1.25 & Damage in W1020 ODS from first slip fault \\
\hline 20 February 2012 & 1.3 & $\begin{array}{l}\text { Six events ( } 40 \text { minutes post-firing on fault) } \\
\text { resulting in damage to W } 1000\end{array}$ \\
\hline
\end{tabular}

Rise firings in the Walters Lode have been found to induce an elevated seismic response, and larger magnitude events, than standard stope firings into voids or existing rises. This increased level of seismicity from rise firings is thought to be due to the larger energy and vibration being transferred into the 
surrounding rock mass in all directions, whereas other stope firings preferentially distribute the blast energy towards the void instead of the surrounding rock mass.

The number of seismic events has decreased since 2009, which may be due to the lower extraction rates from the Walters Lode since then. Even though the overall number of events has reduced, there is a general trend showing the number of larger magnitude events increased between 2010 and mid-2013 at which point event magnitudes began to plateau. This appears to correlate with the extraction of the central access pillar and the increased stresses acting along the first slip fault.

\subsection{Support upgrades}

The original ground support for the development drives were designed for static conditions and predominantly utilised $2.4 \mathrm{~m}$ resin bolts installed over $50 \mathrm{~mm}$ fibrecrete. This initially provided the necessary support to access the ore zone; however, the support design did not consider the potential dynamic requirements when extraction was undertaken. As retreat mining progressed, the levels of seismicity and induced stresses acting on the support began to increase. The support and rock mass began to show signs of stress related damage and failure.

A review of the joint data, and observations from damaging events, indicated that there was a potential for wedge failures in the back of the oredrive relative to the first slip fault. The observed depth of failure, related to these structures, could reach $2.5 \mathrm{~m}$ high.

Determining the dynamic ground support requirements for the Walters Lode required the maximum potential event size to be assessed. This was calculated via the Gutenberg-Richter relationship (frequency-magnitude) distribution chart (Gutenberg \& Richter 1944). The data set starts in November 2009 and shows an estimated design magnitude ( $x$-axis intercept) $M_{L}$ of +1.55 . This is graphically shown in Figure 7. Based on this analysis, it was determined the initial support was not adequate for the largest potential seismic events.

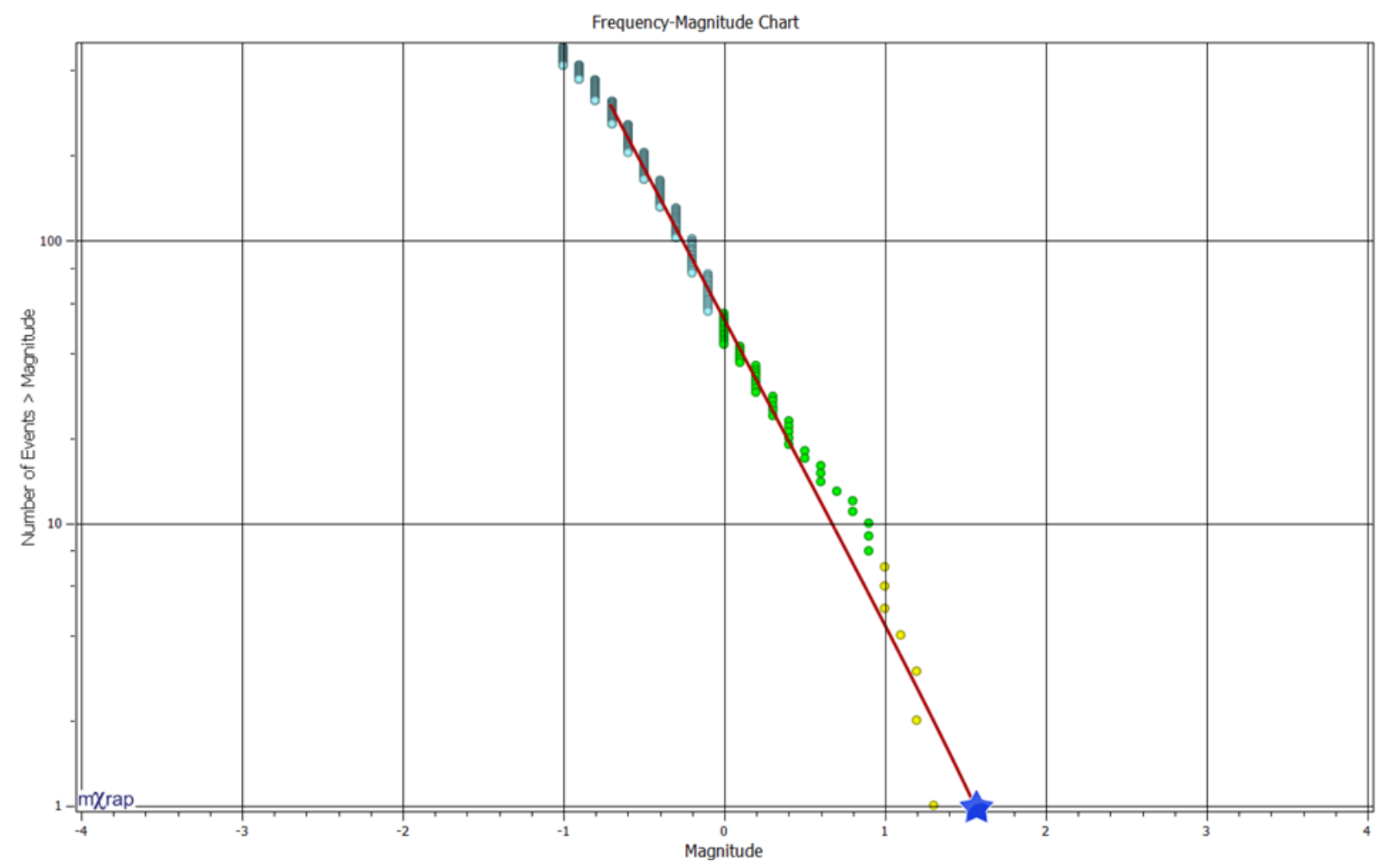

Figure 7 Frequency-magnitude graph

With the maximum seismic event and wedge geometry determined from analyses, the upgrades to ground support could be implemented. Based on the analyses, the support required a greater embedment length 
and also a higher dynamic capability. This led to a seismic ground support regime that could withstand a local magnitude +1.55 event as close as $10 \mathrm{~m}$ from the source. This dynamic support regime utilises nine $2.4 \mathrm{~m}$ split sets per ring, two $6 \mathrm{~m}$ dynamic (de-bonded) $15.2 \mathrm{~mm}$ cables at a ring spacing of $2.5 \mathrm{~m}, 50 \mathrm{~mm}$ fibrecrete and mesh down to $2 \mathrm{~m}$ from the floor on each wall. The $6 \mathrm{~m}$ de-bonded cables provide an additional $3 \mathrm{~m}$ of embedment length to support the larger wedges and allow for energy absorption if dynamic ground movements occur. The mesh transfers the load to adjacent reinforcement, minimises unravelling around cables and contains any potential fibrecrete ejection.

The Factor of Safety (FS) for a $+1.55 \mathrm{ML}$ event at $10 \mathrm{~m}$ was designed using equations proposed by Kaiser et al. (1996) in 'Canadian rockburst support handbook'. A target FS of 1.6 has been targeted and achieved using these calculations:

$$
\begin{gathered}
\text { FS }=\frac{\text { Support Capacity }}{\text { Energy Demand }} \\
\text { FS }=\frac{(\text { Load Capacity } x \text { Displacement Capacity }) \mathrm{x} \text { bolts } / \mathrm{m}^{2}}{\frac{1}{2} \mathrm{mv}^{2}+\text { qmgd }}
\end{gathered}
$$

where:

$$
\begin{aligned}
& \mathrm{m} \quad=\text { mass of ejected rock }(\mathrm{kg}) . \\
& \mathrm{v} \quad=\text { ejection velocity of the block }(\mathrm{m} / \mathrm{s}) . \\
& \mathrm{g} \quad=\text { acceleration due to gravity }\left(\mathrm{m} / \mathrm{s}^{2}\right) . \\
& \mathrm{d} \quad=\text { distance ejected rock has travelled. } \\
& \mathrm{q} \quad=1,0 \text { or }-1 \text { for ejection from the backs, walls or floor respectively. }
\end{aligned}
$$

The upgraded support work very well since implementation and has greatly reduced personnel and equipment exposure to potentially hazardous rockfalls or ejection. Since upgrades were made, large magnitude events (>1.0) have been experienced; however, all damage to the rock mass has been effectively retained by the support scheme.

\subsection{Exclusion zones and re-entry}

Exclusion zones control re-entry into (mainly) stoping areas and development headings after blasting where there is a potential risk of seismicity within a period of time after a stope blast. The seismicity, history and geology of an area are analysed to determine the degree of seismic risk. Re-entry times are determined by seismic data analysed after each stope firing within the Walters Lode. This data includes the event distribution and the number of events recorded per hour within the Walters Lode after a firing. These cumulative hourly events are graphed on an Omori Chart and allow determination of decay constants and a safe re-entry time.

Back-analysis of event distributions post firing the Walters Lode show events occurring between the W920 and W1040 along the first slip fault; this is illustrated in Figure 8. Most events are clustered around the fired stope; however, the damaging effects can be experienced along the fault planes and intersecting drives. Therefore, any stope firings within the Walters Lode incurs an exclusion zone between the W920 and W1040. 


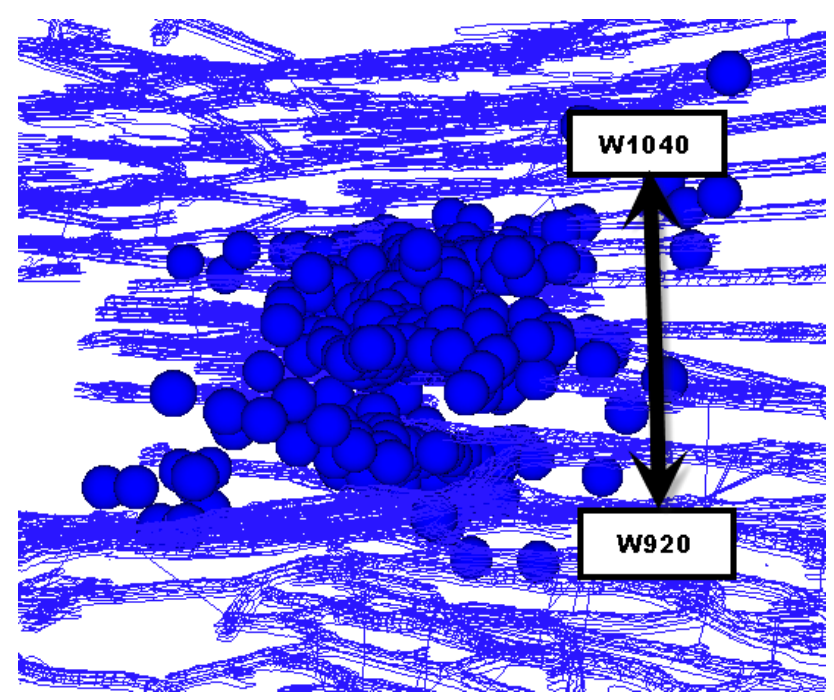

Figure 8 W1000 F Rise Firing 2012

Back-analysis of seismic activity after firing shows that the majority of events occur within the first hour in the Walters Lode. The actual events generally subside faster than the decay curve; however, spikes in the events per hour can occur randomly. These spikes do not necessarily intercept the decay curve; however, it does imply that there are seismic irregularities to account for before any personnel are granted access.

Back-analysis data shows that the level of seismicity decays to background levels within 18-20 hours, therefore the Walters Lode maintains a 24-hour standoff upon firing. An example of the Omori Chart is displayed in Figure 9.

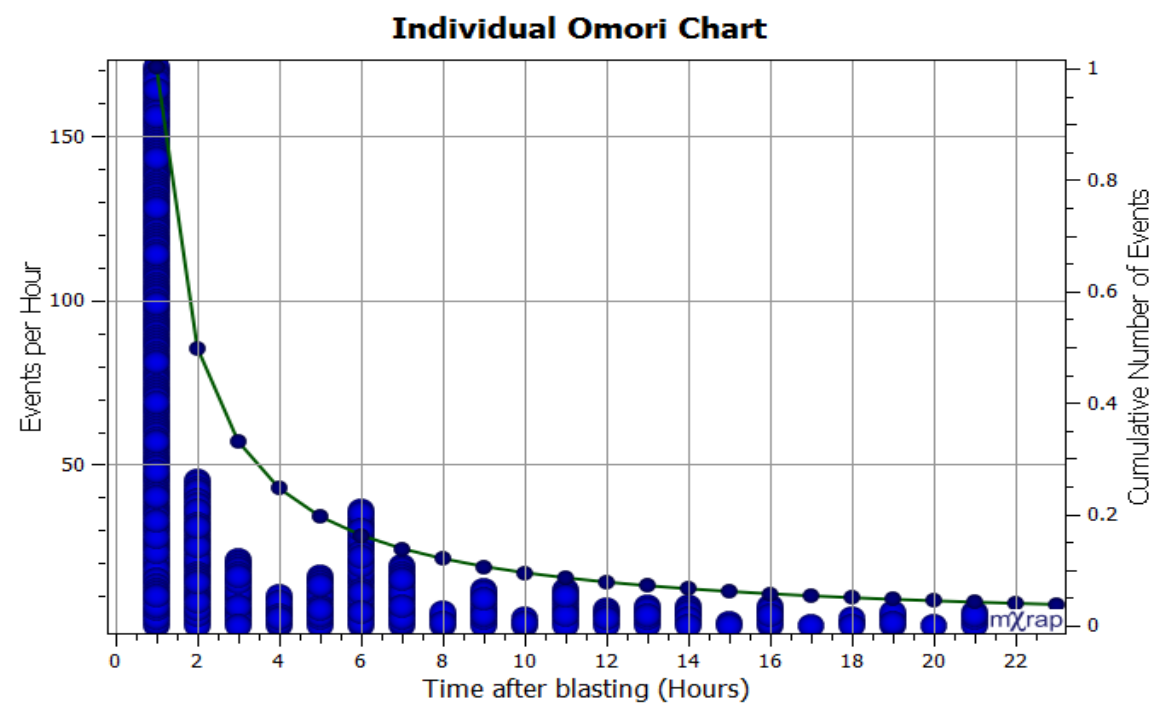

Figure 9 W1000 F Rise Omori Chart

Activity from some seismic sources, particularly those related to fault slip on structures, can show a poor relationship with mine blasting.

\section{$4 \quad$ Walters modelling}

Both linear elastic (Map3D ${ }^{\mathrm{TM}}$ ) and non-linear numerical modelling have been undertaken for the Walters extraction sequence. The aim was to forecast potential areas of damage and seismic potential within the Walters Lode. Initial elastic models were run with various extraction sequences and the proposed stope shapes. 
A Levkovitch-Reusch model was created to provide a basis for non-linear modelling (Beck Engineering Pty Ltd 2012). This model showed that, regardless of initial sequence, the stopes closest to the central access would have the largest seismic response. It was estimated that the vast majority of the Walters Lode ore will be recoverable. However, modelled rock mass damage associated with firing the central access stopes could lead to increased rehabilitation requirements due to constant seismic activity as the central pillar deforms under load. This model was used as the base case for the overall extraction sequence.

Since the non-linear model was conducted, in-house elastic numerical modelling was conducted due to the addition of new stopes outside the current extraction sequences (Figure 10). This modelling complemented the existing modelling to determine if there would be any new significant effects on the rock mass or stresses acting on the faults from further stope extraction. Back-analysis of historical failures and seismic events identified three criteria on which forward planning was made. Table 3 details the failure criterions that were assessed along rock mass parameters from Table 4.

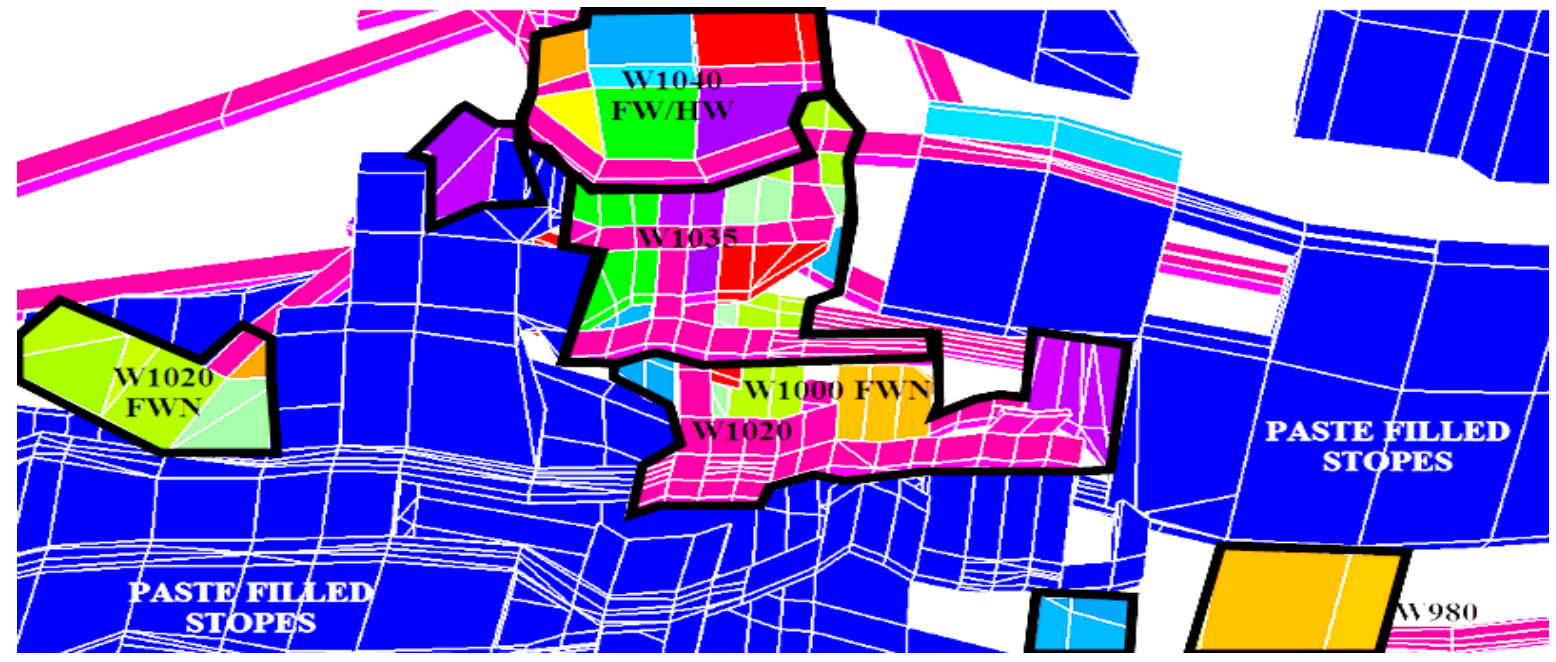

Figure 10 New proposed stopes alongside original stopes in July 2014 (perspective view looking east)

Table 3 Failure criteria assessed within the elastic numerical model (based on back-analysis)

\begin{tabular}{|c|c|c|}
\hline Principle stress sigma $1\left(\sigma_{1}\right)$ & Strength factor B' & Excess shear stress on faults \\
\hline $\begin{array}{l}\text { Slight damage is expected at } \\
25 \% \text { of UCS values ( } 55 \mathrm{MPa} \text { ) } \\
\text { Extensive damage is } \\
\text { expected at } 40-50 \% \text { of UCS } \\
\text { values ( } 88-110 \mathrm{MPa} \text { ) } \\
\text { Complete rock mass failure } \\
\text { at } 60 \% \text { of UCS values } \\
(130 \mathrm{MPa})\end{array}$ & $\begin{array}{l}\text { Method 'B' assumes that the stress } \\
\text { path to failure takes place by } \\
\text { increasing } \sigma_{1} \text { without loss of } \\
\text { confinement } \\
\text { This is representative of a pillar } \\
\text { failure where } \sigma_{1}-\sigma_{3} \text { is considered to } \\
\text { be the driving force } \\
\text { Depth of damage will be measured } \\
\text { when SF-B = } 1\end{array}$ & $\begin{array}{l}\text { Attempts to correlate excess } \\
\text { shear stress values with } \\
\text { previous seismic events show } \\
\text { that in-plane excess shear } \\
\text { strength values }>6 \mathrm{MPa} \text { are an } \\
\text { appropriate value where shear } \\
\text { related damage on structures } \\
\text { occurs }\end{array}$ \\
\hline
\end{tabular}


Table 4 Parameters associated with Walters Lode numerical modelling

\begin{tabular}{|c|c|c|c|c|c|}
\hline $\begin{array}{l}\text { In situ stress } \\
\text { values }\end{array}$ & $\begin{array}{l}\text { Hoek-Brown } \\
\text { classification }\end{array}$ & $\begin{array}{l}\text { Hoek-Brown } \\
\text { criterion }\end{array}$ & $\begin{array}{l}\text { Mohr-Coulomb } \\
\text { fit }\end{array}$ & $\begin{array}{l}\text { Rock mass } \\
\text { parameters }\end{array}$ & $\begin{array}{l}\text { Paste } \\
\text { parameters }\end{array}$ \\
\hline $\begin{array}{l}\sigma_{1}=0.079 \mathrm{MPa} / \mathrm{m} \\
\text { trending at } 90^{\circ} \\
\text { and plunging } \\
\text { down } 12^{\circ} \\
\sigma_{2}=0.034 \mathrm{MPa} / \mathrm{m} \\
\sigma_{3}=0.029 \mathrm{Mpa} / \mathrm{m}\end{array}$ & $\begin{array}{l}\mathrm{UCS}^{1}=220 \mathrm{MPa} \\
\mathrm{GSI}^{2}=75 \\
\mathrm{Mi}^{3}=16\end{array}$ & $\begin{array}{l}M b^{4}=6.55175 \\
s^{5}=0.0621765 \\
a^{5}=0.500911\end{array}$ & $\begin{array}{l}\text { Cohesion = } \\
18.9 \mathrm{MPa} \\
\text { Friction angle = } \\
41.9^{\circ}\end{array}$ & $\begin{array}{l}\text { Tension }=-2.0 \mathrm{MPa} \\
\text { Strength = 54.7 MPa } \\
\text { Global strength }= \\
84.7 \mathrm{MPa} \\
\text { Deformation modulus = } \\
42 \mathrm{GPa}\end{array}$ & $\begin{array}{l}1.0 \mathrm{MPa} \\
\text { Allows the } \\
\text { model to } \\
\text { observe } \\
\text { passive } \\
\text { confinement } \\
\text { from paste }\end{array}$ \\
\hline
\end{tabular}

${ }^{1}$ Uniaxial compressive strength; ${ }^{2}$ geological strength index; ${ }^{3}$ material constant; ${ }^{4}$ reduced value for the rock mass of the material constant mi;

${ }^{5}$ constants based on rock mass characteristics

As the extraction proceeded, modelling indicated that the majority of stopes located behind previously extracted and paste filled stopes were in a stress 'shadow' and were not expected to have increased seismicity. Stress concentrations remained within the central pillar access areas. Also, stopes which encroached on smaller sill pillars showed an increased field stress (70 $\mathrm{MPa}+)$ between the paste above and the stopes. This higher stress criterion indicated that $4 \mathrm{~m}$ out of a $6 \mathrm{~m}$ pillar could be expected to fail upon firing or induced seismic responses. Therefore, stopes that reduced the sill pillar were considered unsafe to mine (Figure 11).

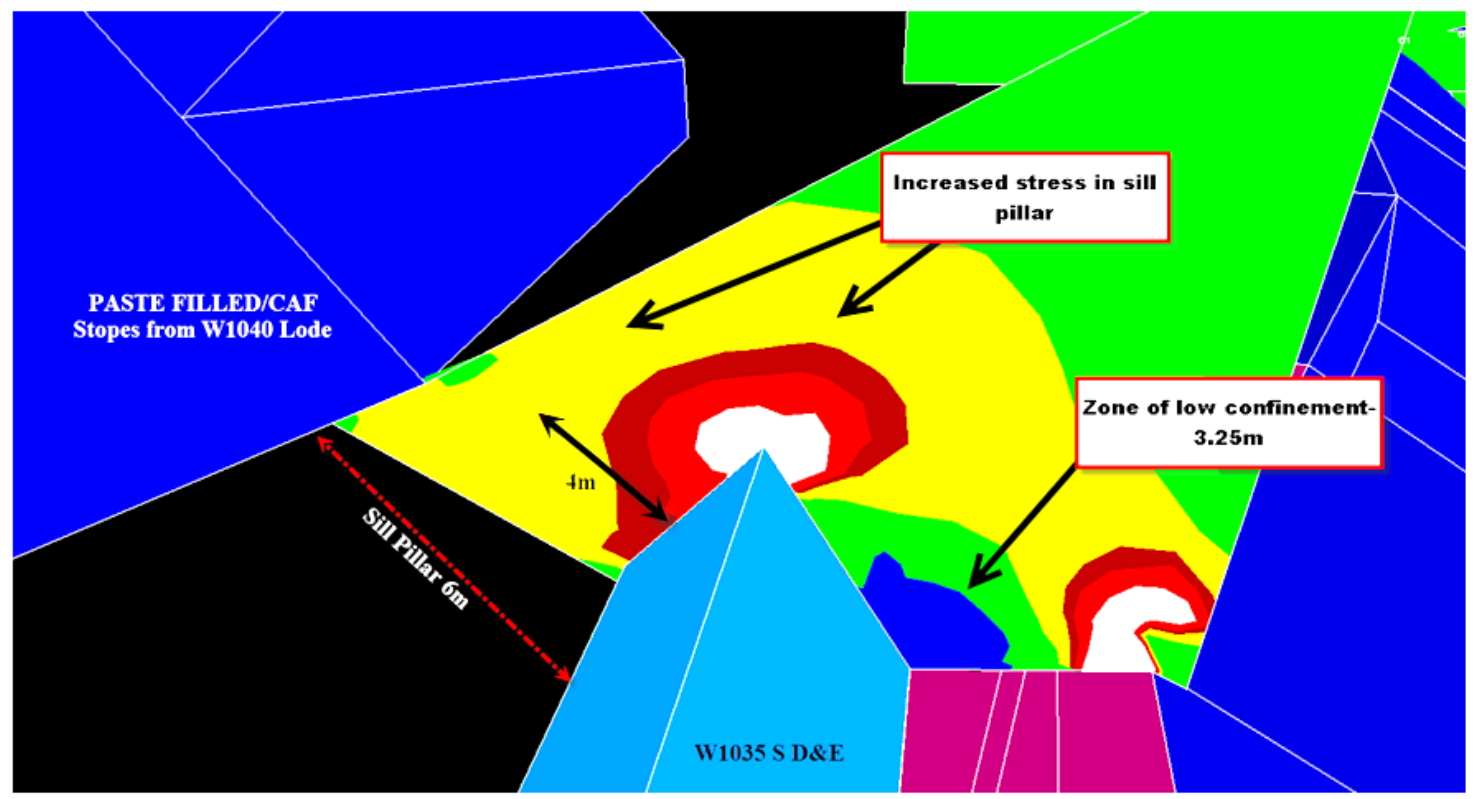

Figure 11 W1035 S D\&E proposed shape in the sill pillar

The modelling indicated high $\sigma_{1}$ values approximately $3.2 \mathrm{~m}$ into the backs of the drive (Figure 12). This coincides with the anticipated wedge height potential discussed in Section 3.1. The de-bonded cable support will still have $2.8 \mathrm{~m}$ of embedment within competent rock and should still be effective through the entire stoping sequence. In addition, all brows in the Walters Lode will have extra cable support. 


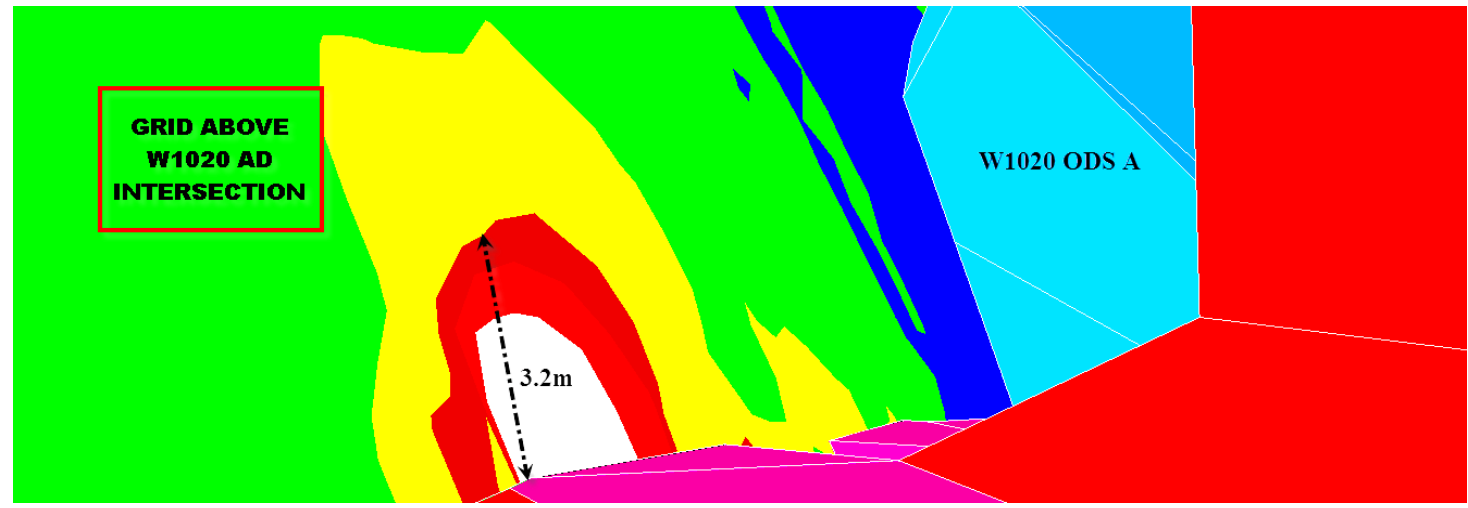

Figure 12 Rock mass damage potential in drives

It was found that loss of confinement in the HW could be a primary cause of overbreak within the majority of inclined shapes, especially with stopes which were overcut by extracted stopes above. The loss in confinement is because the rock mass in the HW is only confined on two abutments (Figure 13).
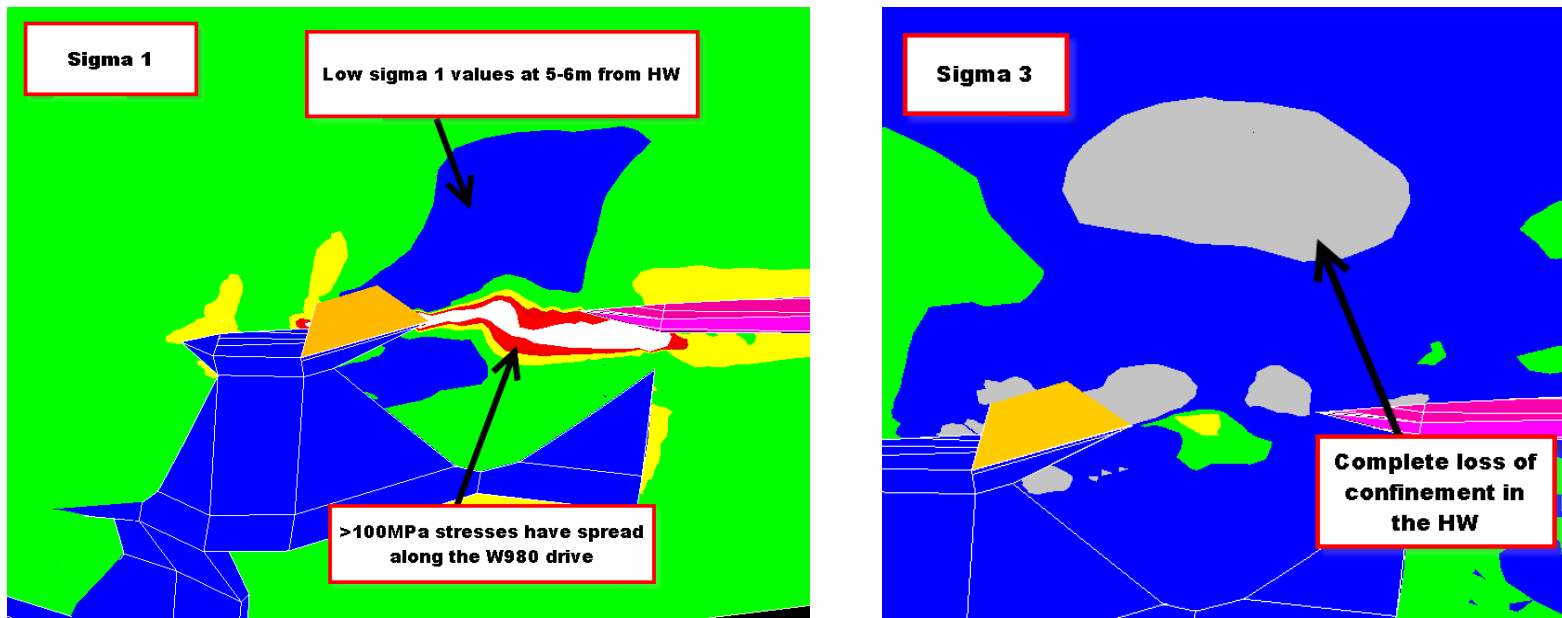

Figure 13 Loss of confinement upon extracting stopes central to stress window

The modelling also allowed for shear stress changes to be recognised at certain steps of the mining sequence. It was found that certain stopes could initiate a regional stress change along the fault structures. The mining steps that showed a sudden change were flagged as high risk stopes and were re-sequenced, where possible, to late in the Walters Lode sequence. An example of this is the W980 HW A (Figure 14) which induces a regional shear stress change on the first slip fault, and has potential to cause seismic induced damage and fall out.
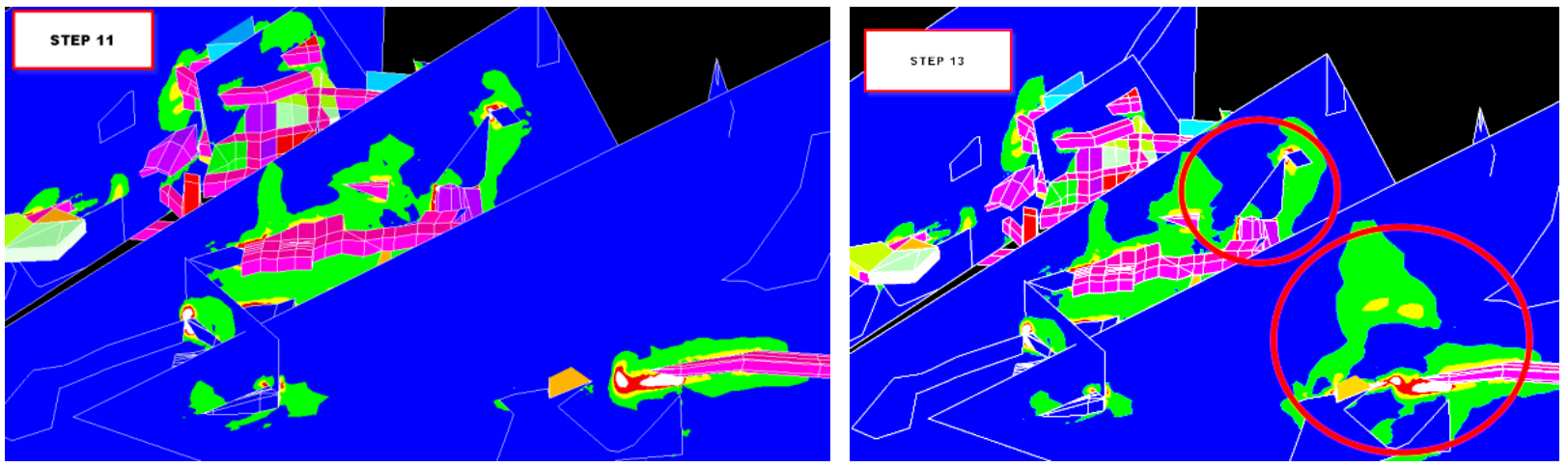

Figure 14 Regional shear stress change pre and post blasting W980 HW A Stope 
Based on results from modelling, the following recommendations were made to management, and documented in a Walters Lode sequence report:

- Ground support needed to be upgraded in 1020 and 1040 Levels (HW/FW development access when it occurs) to account for the maximum depth of damage of $3.2 \mathrm{~m}$ into the backs.

- Even after all the ground support upgrade works are completed, occasional rehabilitation works will be required.

- Some ore reserves may not be mined, and a recovery of $80 \%$ is estimated.

- The numerical model suggests that all stoping activities will correspond with high seismic event potential.

- Central access pillar stopes such as on 1000 and 1020 Levels are to be mass blasted where possible and re-entry will be determined by the seismicity levels.

- Any stopes that are left as pillars should be de-stressed by means of pre-condition blasting, so that they do not attract seismicity.

- Avoid stoping the $\mathrm{W} 1035 \mathrm{H} / \mathrm{G}$ and W980 stopes at the same time. This could cause the pillar to crush and increase the shear stress along the first slip fault. This is illustrated in Figure 14.

- Shape changes to the stopes that undercut drives or stopes should be re-evaluated, as this may help reduce stress related failures and potential wedge fall outs.

\section{$5 \quad$ Walters Lode management protocols}

With all the seismic back-analysis data, in-house and outsourced numerical modelling, proposed stope shapes and support requirements could be determined. A set of protocols were implemented into the planning and scheduled performance of the Walters Lode; these are detailed in Table 5.

Table 5 Management protocols for the Walters Lode extraction

\begin{tabular}{|c|c|c|c|}
\hline Stope design & Extraction & Seismicity & Ground support \\
\hline $\begin{array}{l}\text { Stopes are to be designed to } \\
\text { the first slip fault contact. } \\
\text { Dilution factors are to be } \\
\text { adjusted based on numerical } \\
\text { modelling results and } \\
\text { expected depth of failure. } \\
\text { Economics of stopes to be } \\
\text { discussed with management } \\
\text { pending this information. } \\
\text { HR of } 5 \text { is considered a } \\
\text { maximum for inclined stopes. }\end{array}$ & $\begin{array}{l}\text { No more than three } \\
\text { stopes are to be left open } \\
\text { at a time without paste } \\
\text { filling. } \\
\text { Follow the extraction in } \\
\text { the approved sequence. } \\
\text { Stopes are not to be left } \\
\text { idle, they should be } \\
\text { bogged clean between } \\
\text { each firing and } \\
\text { completed as soon as } \\
\text { possible. }\end{array}$ & $\begin{array}{l}\text { Exclusion zones } \\
\text { upon stope firing } \\
\text { will be affected } \\
\text { between the W920 } \\
\text { and W1040. } \\
\text { All exclusion zones } \\
\text { will be for } 24 \text { hours } \\
\text { (and potentially } \\
\text { longer) and must be } \\
\text { determined using } \\
\text { an Omori Analysis } \\
\text { and event } \\
\text { distribution. }\end{array}$ & $\begin{array}{l}\text { All drives and central } \\
\text { access areas } \\
\text { associated with the } \\
\text { first slip fault require } \\
\text { dynamic ground } \\
\text { support upgrades } \\
\text { before any stoping } \\
\text { can commence on } \\
\text { the level. } \\
\text { All brows are to be } \\
\text { supported with } \\
\text { additional brow } \\
\text { cables. }\end{array}$ \\
\hline
\end{tabular}

\section{Conclusion}

The analysis revealed that mining the Walters Lode comes with inherent risks to production and personnel, regardless of the chosen mining sequence. Increased seismicity and rock mass damage are an inevitable consequence of reducing the regional pillar dimensions. This has been factored into the schedule. 
The final analysis showed that majority of safety issues could be mitigated with administrative control systems and appropriate ground control standards.

In addition to these management protocols, extraction will be closely monitored to assess whether the seismic response and stope performance matches the modelling results. With new information available after each stope firing, there is the ability to further calibrate the model to provide an updated extraction scenario and highlight any new or changing risks.

Overall, the performance of the stope extraction has been as expected, with dilution factors being slightly less than the modelling results. In accordance with the Australasian Joint Ore Reserves Committee (JORC 2012) requirements, indicated modelled dilution was incorporated into the ore reserve economics (as geotechnical conditions have a material effect). The seismicity has been consistent with the modelling results to date. However, the event magnitudes have not been greater than the +1.3 event which occurred on 20 February 2012. There has been no fall of ground or chronic deterioration of support within the Walters Lode since the support upgrades were completed in 2013. It is expected that the upgrades have dramatically reduced the amount of rehabilitation work required.

In conclusion, it would be considered a critical safety and production risk if these analytical methods were not conducted for a regional pillar scenario. Without the forecasted effects of mining, the Walters Lode would have been an unknown, and would likely have led to unexpected personnel and equipment exposure to rockfall hazards; increased rehabilitation after stope firings; brow failures; additional over break; heightened seismic responses; and even the potential for sterilisation of the remaining ore reserves.

\section{Acknowledgement}

The authors thank the following organisations and persons for providing support and involvement with the Walters regional pillar extraction.

- Darlot Gold Mine - for providing images and support.

- Emma Jones and Christopher Chester - Barrick Gold of Australia.

- David Beck and Charles Lilley - Beck Engineering Pty Ltd.

- Johan Wesseloo and Paul Harris - Australian Centre for Geomechanics.

\section{References}

Barton, N, Lien, R \& Lunde, J 1974, 'Engineering classification of rock masses for design of tunnel support', Rock Mechanics and Rock Engineering, vol. 6, no. 4, pp. 189-236.

Beck Engineering Pty Ltd 2012, Calibration and forward analysis of Boon North - middle Walters stress window area', report, Beck Engineering Pty Ltd, Chatswood West.

Gutenberg, R \& Richter, CF 1944, 'Frequency of earthquakes in California', Bulletin of the Seismological Society of America, vol. 34, pp. $185-188$.

JORC 2012, Joint Ore Reserves Committee, JORC Code: Australasian Code for Reporting of Exploration Results, Mineral Resources and Ore Reserves, Joint Ore Reserves Committee, South Carlton, pp. 18-19, http://www.jorc.org/docs/JORC_code_2012.pdf Kaiser, PK, McCreath, DR \& Tannant, DD 1996, Canadian rockburst support handbook, Geomechanics Research Centre, Sudbury. Mitchell, RJ \& Roettger, JJ 1989, 'Analysis and modelling of sill pillars', in FP Hassani, MJ Scoble \& TR Yu (eds), Proceedings of the Fourth International Symposium on Mining with Backfill, Innovations in Mining Backfill Technology, Balkema, Rotterdam, pp. 53-62. 